\title{
Residential Load Management System using IoT
}

\author{
${ }^{1}$ Zahira Tabassum, ${ }^{2}$ Akash D, ${ }^{3}$ Bavaji J, ${ }^{4}$ Desha R, ${ }^{5}$ Anil Kumar \\ ${ }^{1}$ Assoc. Professor, HBKCE-Bengaluru, Karnataka, India \\ ${ }^{2}$ Student, HBKCE-Bengaluru, Karnataka, India \\ ${ }^{3}$ Student, HBKCE-Bengaluru, Karnataka, India \\ ${ }^{4}$ Student, HBKCE-Bengaluru, Karnataka, India \\ ${ }^{5}$ Student, HBKCE-Bengaluru, Karnataka, India \\ $\frac{1 \text { zahirat.ec@hkbk.edu.in, }{ }^{2} \text { akashanantwal01@gmail.com, }}{\text { 3issacbavaji@gmail.com, }^{4} \text { kolekardesha@gmail.com, }}$ \\ 5anilkumarjnvd123@gmail.com
}

\begin{abstract}
In the recent years the technological growth is observed at a higher pace and as the technology evolves the dependency of human on technology also increases and as the result the number of appliances or devices per household increases. The increase in the number of appliances in a household contribute a major share in increasing the demand for electricity during the peak hours at a residential level. The conventional method of meeting the demand by generating power or setting up of new generating plants is one of non-feasible method and it impacts the many factors such as cost, pollution, losses etc. One of the possible solutions for the control of demand is by Demand Side Management. The paper proposes a implementation of a Demand Side Management for Residential Users using IoT,
\end{abstract}

Keywords: Time of Use Pricing, Load shifting, Peak Demand

\section{Introduction}

In recent years the technology has evolved exponentially and the electricity rate has increased proportionally. The home appliances sector is considered a one of the fastest-growing industry in the Indian market, the recent years the world has faced lots of challenges due to the pandemic, it has made a huge impact on the economy as well as the lifestyle of the people and it is noted that all India electricity consumption dropped by $22 \%$. Due to the imposed lockdown the demand for the electricity by the Industrial and Manufacturing sectors noted a decline but on the other hand the demand at residential side increased as people spent most of the time in the house and worked through online mode.

The observed data released by NLDC, in the set of three years i.e., 2021-2020-2019 the demand for power in the month of the march for the year 2021 it stood up to 170.6 GW from $157 \mathrm{GW}$ in the year 2020 and that of $163 \mathrm{GW}$ in March of 2019. 
The conventional method of meeting the demand is by opting for generating more power or by installing the new power plants. For generating more amount power requires large number of fuels which lead to the release of toxic gases in the environment and for setting up new power generating plants and laying of new transmission and distribution requires enormous amount of financial support and the A\&T losses are also major constraint for the utility.

In order to overcome these constraints, the demand side management provides a optimum solution in which the consumer plays an important role in controlling the demand of the electricity. Demand Side Management can be explained as the actions taken by users end to change the amount or timing of energy consumption. Utility DSM events offer greater variety of actions that help in reduction of energy consumption and eventually the user energy expense.

The classification of the DSM programs is shown in fig 1.

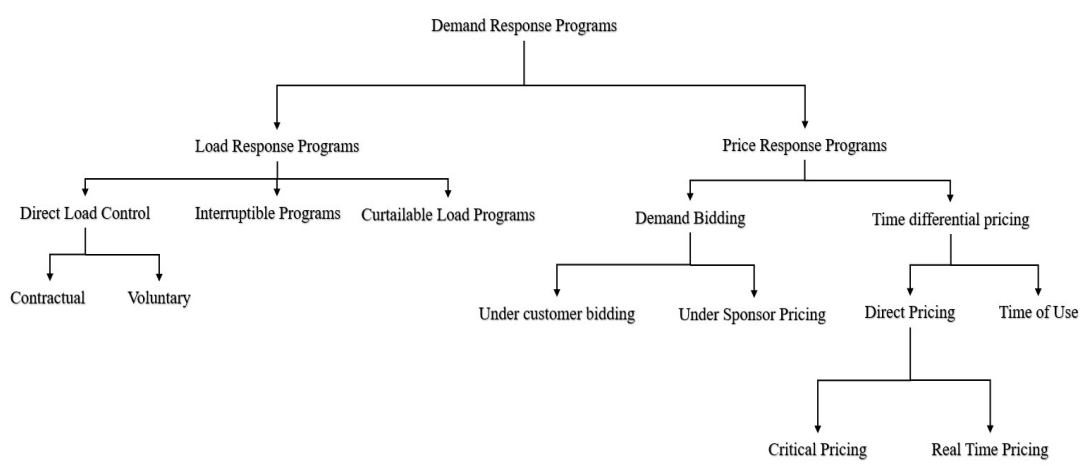

Fig 1: Demand Response Programs

In this paper we propose a Load Management System using IoT, the system is divided of two section one is the monitoring section and second is the IoT section in which the user notified about his current usage of power and alert notification through the help of telegram mobile application.

The monitoring section is done with the help of ACS712 5amp current sensor which gives the current values of both $\mathrm{AC} / \mathrm{DC}$ device. For the demonstration purpose we have considered two house monitoring model with two loads per house. The Loads considered in the protype is $2 \mathrm{LED}$ bulbs of $15 \mathrm{~W}$ and $9 \mathrm{~W}$ power rating respectively and 2 Incandescent light bulbs of $40 \mathrm{~W}$ and $60 \mathrm{~W}$ power rating respectively.

\section{Literature Review}

Paper [1] shows the results of a survey study together with the measured power values of home appliances are used to generate realistic representative residential load profiles for a working family in Turkey. In the survey, appliance use time and duration of the appliance usage are the main questions as combining this information with the measured power values give total residential demand. Four representative residential demand profiles for summer/winter weekday and summer/winter weekend are given and with the help of these representative load 
profiles provide valuable information such as peak demand intervals. The approximate peak demand about $7 \mathrm{~kW}$ in this study to utility companies so that they can manage their generation asset more efficiently.

The paper [2] presents a demand side management technique which is primarily based on the load shifting, with a focus on ranking of flexible load to be shifted first. From the resulted graph, it can be observed that when loads are sorted in descending order, the optimized load curve is better than the curve obtained in rest of the cases. The final load curve is close to the average curve when the loads are sorted in descending order. One of the main advantages which the proposed technique poses is the flexibility to shift the load which allows to implement the consumer's lifestyle choices.

Paper [3] proposed the load shifting technique for load management on the consumer side. The load shifting algorithm successfully works to level or smooth out the load demand over the day without a decrease in total energy consumption. A load shifting algorithm is developed by using classical approach, which take less time for execution. The strategy implemented to shift the consumer loads to appropriate time in order to reduce the peak demand and utility will get a relief. The load shifting algorithm can shift controllable loads to the appropriate time of the day means off-peak hours in order to reduce peak demand. This proposed algorithm will not only reduce consumer costs, but will also reduce generation cost.

The paper [4] proposed Demand Side Management system for demand response applications which can effectively control and manage operation of various appliance to keep the total consumption below a threshold. The proposed DSM takes into account both the load priority and user preferences. Thus, the work provides a low-cost, flexible, user friendly, and very secure architecture for implementing a Demand Side Management System. Hardware results indicate the effectiveness of the proposed DSM Strategy and the profit to the users in their electricity bills.

\section{Methodology}

The overview of the proposed Demand Side Management system is shown in fig 2 . The basic idea is to design and develop user friendly interface and control functionalities. In our system we have considered the working day into three different slots peak hours, normal hours and off-peak hours and for each slot is been provided with a threshold. During these slots the loads are being monitored and with the help of current sensor we get the current consumption of the loads and the respective power is been calculated in terms of $\mathrm{kWh}$. The obtained power is compared with the threshold set and we have used an 16x2 alphanumeric display as an in-home display where user can see his usage. A two-channel relay module is used to control the function of terminating of power supply of the two-house supplies and Arduino Uno is used as a main microcontroller interfaced with ACS712, LCD display, Relay modules. For IoT part Implementation we have used NodeMCU ESP8266 module to interface with telegram mobile application. 


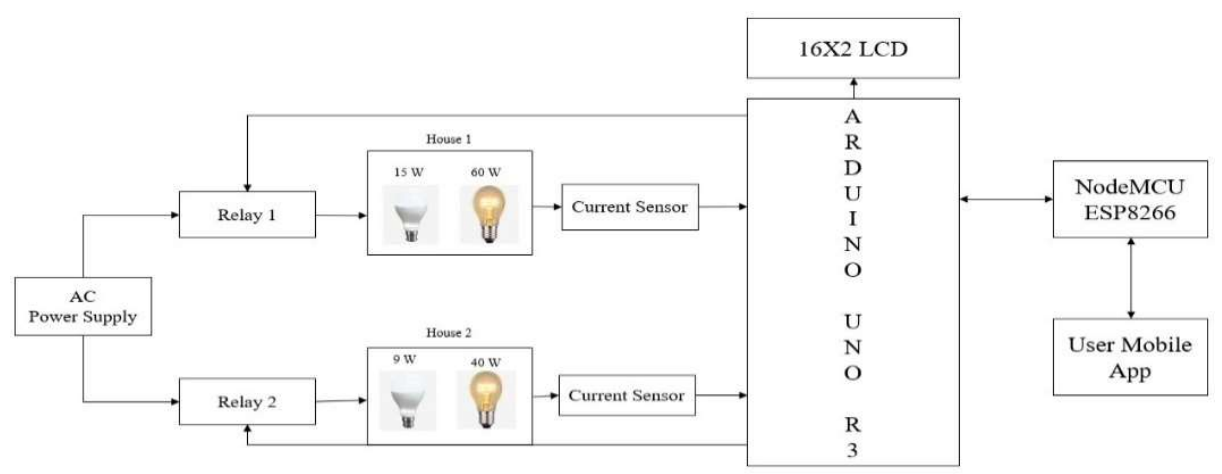

Fig 2 Block diagram

In these scenario three cases are considered as follows:

Case 1: When the user is about reach the threshold and limits his usage.

In this case the user monitors the loads and when the user reaches the fifty percent of the threshold the user gets an alert message that he is exceeding his energy limit. When the user sees the message, he will turn off loads and use at different time and hence the threshold will be maintained and the demand will be controlled by opting the load shifting method.

Case 2: When the user reaches the threshold and wishes to continue usage with double tariff rate.

In this case as the threshold is exceeded an alert message will be send to the user and a Permission is asked whether he want to continue the electricity usage with tariff rate of doubled. In this condition if the user agrees to condition for electricity rate doubled the power supply will be not be terminated and he can use the electricity for that slot at a higher price, this condition supports the Time of Use pricing.

Case 3: When the user reaches the threshold and does not wishes to continue.

In this case as the threshold is exceeded an alert message will be send to the user and a Permission is asked whether he wants to continue the electricity usage with double tariff rate and if the consumer says a No to the permission the power supply of the house which has exceeded the threshold the power supply will be terminated for that slot.

The hardware setup of the prototype is shown in fig 3 below

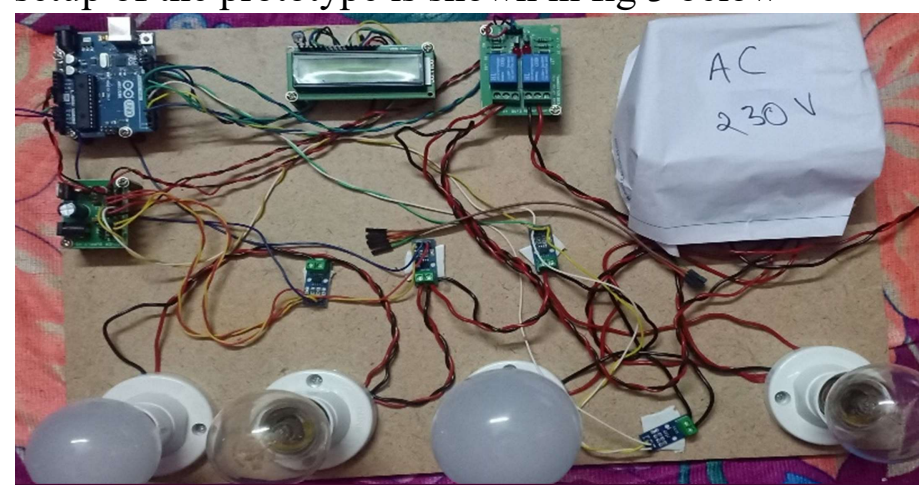

Fig 3 Hardware Prototype Setup 


\section{Results and Analysis}

For setting up the threshold for the slots, few recordings were carried out and compared with the theoretical calculation and the recording were carried out for duration of difference of 5 minutes i.e., for 5 minutes, 10 minutes, and 15 minutes the reading are shown in the table 1 below.

\begin{tabular}{|l|l|l|l|l|l|l|}
\hline Type of Load & \multicolumn{2}{|l|}{5 minute duration } & \multicolumn{2}{l}{10 minute duration } & \multicolumn{2}{l}{15 minute duration } \\
\cline { 2 - 7 } & $\begin{array}{l}\text { Recorded } \\
\text { Value }\end{array}$ & $\begin{array}{l}\text { Calculated } \\
\text { Value }\end{array}$ & $\begin{array}{l}\text { Recorded } \\
\text { Value }\end{array}$ & $\begin{array}{l}\text { Calculated } \\
\text { Value }\end{array}$ & $\begin{array}{l}\text { Recorded } \\
\text { Value }\end{array}$ & $\begin{array}{l}\text { Calculated } \\
\text { Value }\end{array}$ \\
\hline Bulb 40 Watts & 0.00381 & 0.003333 & 0.007419 & 0.00666 & 0.01111 & 0.001 \\
\hline LED 15 Watts & 0.001155 & 0.00125 & 0.002099 & 0.0025 & 0.0031343 & 0.00375 \\
\hline Bulb 60 Watts & 0.00490 & 0.005 & 0.00973 & 0.01 & 0.0146 & 0.015 \\
\hline LED 9 Watts & 0.000798 & 0.00075 & 0.00111 & 0.0015 & 0.001654 & 0.00225 \\
\hline
\end{tabular}

Table 1: Observation Table
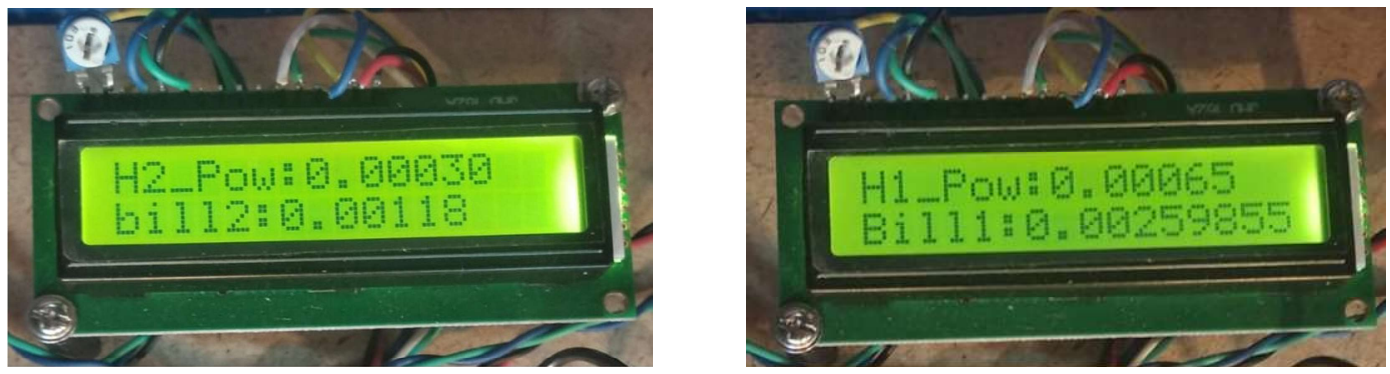

Fig 4 Power (in kWh) and bill generated displayed on LCD Screen

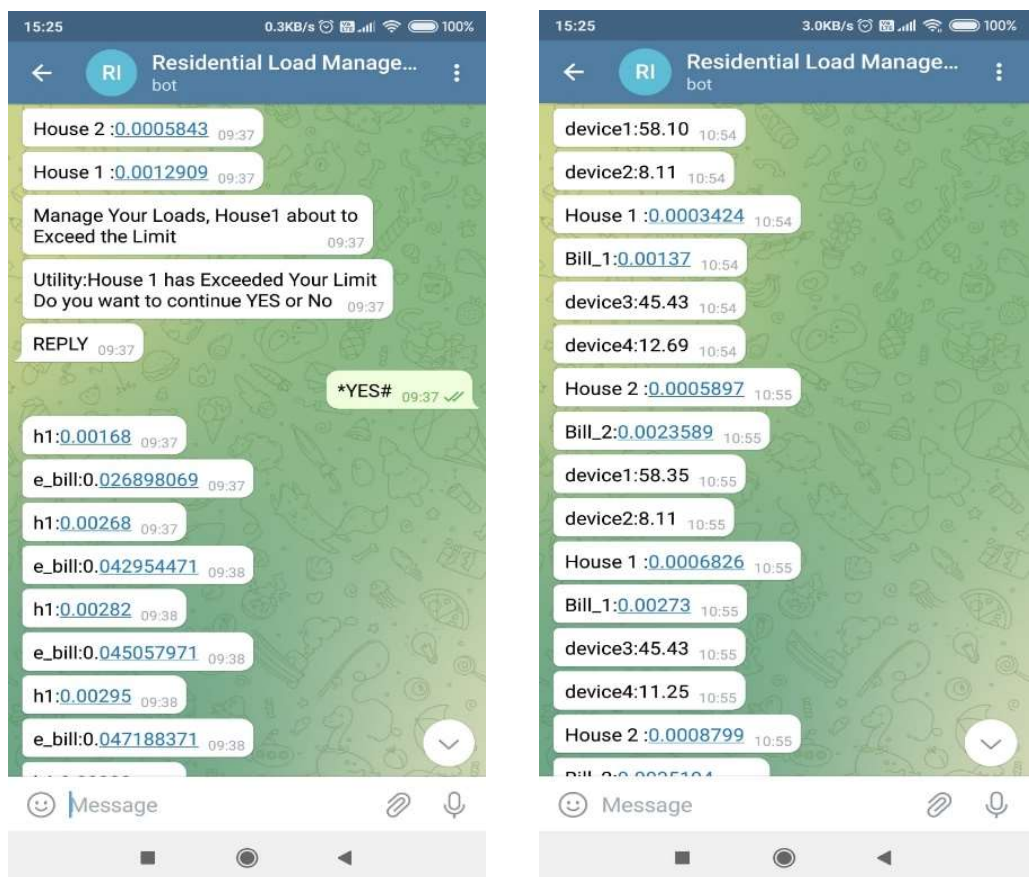

Fig 5 Alert notification and Power Monitoring on Telegram App 


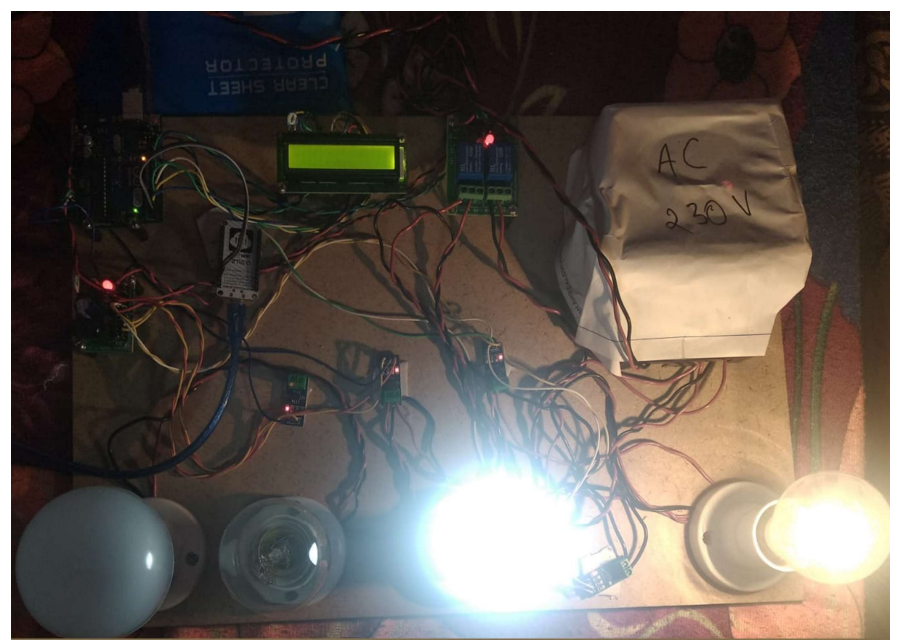

Fig 6 User Wishes to Discontinue Usage (House 2 Power Supply terminated)

\section{CONCLUSION}

The demand side management strategy helps in active participation in controlling the peak demand and avoids the utility from generating more amount of power and installing the new generating plants. It helps in reduction in the rate of electricity and does not hinder the normal lifestyle. The proposed system is hybrid of three type of strategy of Load shifting, Time of Use Pricing and Direct Load Control. With the real time monitoring and alert notification before the reaching threshold the user can opt for Load Shifting technique and reduce the peak demand, the use double electricity employs the Time of Use pricing where the rate of electricity is at higher rate due to the peak demand and the last case where the user disagrees to use the electricity at double rate the power supply of the house is terminated employing the Direct Load Control. The drawback of the system is the user has to face the discomfort of having the power supply being terminated on disagreeing with the condition and the individual load monitoring makes the system complex.

\section{ACKNOWLEDGEMENT}

We express our heartfelt gratitude to the college management of HKBK College of Engineering, Bengaluru for enabling us to carry out the project work with all the resources and subsequent publication. Also, we express our sincere gratitude to Visvesvaraya Technological Institute (VTU), Belagavi for providing us the platform.

\section{References}

[1] Onur Elma, Ŭ̆ur S. Selamoğullar, "A Survey of a Residential Load Profile for Demand Side Management Systems, ” 2017 the $5^{\text {th }}$ IEEE International Conference on Smart Energy Grid Engineering.

[2] Kamakshi Prashadini Swain, Mala De, "Analysis of Effectiveness of Flexible

Load Shifting Order on Optimum DSM, "2017 IEEE International WIE

Conference on Electrical and Computer Engineering (WIECON-ECE) 18-19

December 2017.

[3] Alpana Sinha, Mala de, "Load Shifting Technique for Reduction of peak

Generation Capacity Requirement of Peak Generation Capacity Requirement in 
Smart Grid," $1^{\text {st }}$ IEEE international conference on power electronics, Intelligent Control and Energy Systems (ICPEICES-2016).

[4] Anjana S.P and Angel T.S, "Intelligent Demand Side Management for Residential Users in a Smart Micro-grid," 2017 IEEE International Conference on technological advancements in Power and Energy (TAP Energy) 978-1-53864021-0/17. 